\title{
Development of Methodology for Vulnerability Assessment of Chemical Accident in Terrestrial Ecosystem: (2) Focusing on the Herbs
}

\author{
Yooeun Chae $^{\oplus} \cdot$ Lia Kim $^{\oplus} \cdot$ Rongxue Cui $^{\oplus} \cdot$ Jieun Lee $^{\oplus} \cdot$ Youn-Joo $^{\dagger}{ }^{\dagger \oplus}$
}

Department of Environmental Health Science, Konkuk University

(Received September 22, 2020; Revised November 14, 2020; Accepted November 18, 2020)

Objective: As the industry rapidly develops in modern society, the use of chemicals increases and people and various organism living in terrestrial environments are exposed to these chemicals in large quantities. Chemical accidents frequently occur around the world, and these accidents could cause fatal damage to the terrestrial ecosystem. When the terrestrial ecosystem is exposed to highly toxic chemicals, soil functions as well as living organisms in the terrestrial ecosystem could be severely damaged. Countermeasures against chemical accidents and chemicals are required to prevent such damage and for this purpose, systematic vulnerability assessment techniques should be developed to prepare terrestrial ecosystem management for chemical accidents. For this purpose, this study is conducted to develop chemical vulnerability assessment techniques based on biological characteristics of plants.

Method: First, we selected 215 species among herb plants according to the domestic distribution and establish various vulnerability indicators that can be evaluated according to the exposure and recovery categories.

Results and Discussion: As a result of vulnerability scoring for 215 herbs species, the most vulnerable species were Humulus japonicus, Linum usitatissimum, Psilotum nudum, Trigonotis peduncularis, and Lamium amplexicaule. The least vulnerable species were Miscanthus sinensis, Dactylis glomerata, Spodiopogon sibiricus, and Polygonum filiforme.

Conclusions: Terrestrial ecosystem is a main stage of human activity, so there is a high risk of chemical accidents as a large amount of chemicals are used. By utilizing this terrestrial ecosystem vulnerability assessment proposed in this study, we can prioritize the vulnerability of chemicals on the terrestrial ecosystem and use this technique to manage chemical accidents and chemicals and prepare countermeasures.

Keywords: Vulnerability, Terrestrial Ecosystem, Soil, Chemical Accident, Plant

The Korean text of this paper can be translated into multiple languages on the website of http://jksee.or.kr through Google Translator. 


\section{연구논문}

\section{화학사고 대비 육상생태 취약성 평가기법 개발 연구: (2) 초본류를 중심으로}

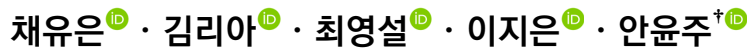

건국대학교 환경보건과학과

목적: 현대사회에서 산업이 급속도로 발전함에 따라 화학물질의 사용량은 증가하며, 육상 환경에서 서식 및 활동 하는 사람과 다양한 생물들이 이러한 화학물질에 다량 노출된다. 전 세계적으로 화학물질에 의한 사고가 빈번하게 발생하며 화학물질 사고에 의해 육상 생태계는 치명적인 피해를 입게 된다. 고독성의 화학물질이 육상 생태계로 다량 노출될 경우, 육상 생태계에 서식하는 생물들뿐 아니라 토양 기능 또한 큰 피해를 입게 된다. 이러한 피해를 방지하기 위하여 화학사고 및 화학물질에 대한 대응책이 요구되며, 체계적인 취약성 평가 기법을 개발하여 화학사 고 발생을 대비한 육상 생태계 관리 방안을 마련할 필요가 있다. 본 연구에서는 이러한 목적으로 생물 특성 기반의 화학사고 및 화학물질 취약성 평가 기법을 개발하고자 하였다.

연구방법: 국내 분포에 따라 선정된 215종의 초본에 대하여 노출(exposure) 및 회복(recovery) 범주에 따라 이를 평 가할 수 있는 다양한 취약성 인자(vulnerability indicator)를 설정하고, 각 식물의 특성에 따라 인자별로 배점화를 수 행, 이를 합산하여 식물의 화학사고에 대한 취약성을 정량화하였다.

결과 및 토의: 초본 215종에 대한 취약성 인자 설정 및 배점화 결과, 환삼덩굴, 아마, 솔잎난, 꽃마리 및 광대나물이 최상위 취약종으로 확인되었으며, 억새, 오리새, 큰기름새 및 이삭여뀌가 최하위 취약종으로 확인되었다.

결론 : 육상 생태계는 인간 활동의 주요 무대가 되며 다량의 화학물질이 사용되는 만큼 화학사고로 인한 큰 위험성 이 존재한다. 본 연구에서 제안하는 육상 생태계 취약성 평가를 활용, 화학물질의 육상 생태계에 대한 취약성을 우 선적으로 평가하여 이를 화학사고 및 화학물질 관리와 대응방안 마련에 활용할 수 있을 것이다.

주제어: 취약성, 육상 생태계, 토양, 화학사고, 식물

\section{1. 서론}

육상 생태계(Terrestrial ecosystem)는 토양을 기반으로 삶 을 영위하는 사람을 포함한 생물(organism)들의 생활 기반 이다. ${ }^{1)}$ 생물들은 토양 내에 서식하거나 또는 토양에 서식하 는 생물을 에너지원으로 삼기 때문에 토양 환경은 육상에 서식하는 모든 생물들에게 매우 중요한 환경 매체라고 할 수 있다. 따라서 토양 환경 오염이나 토양 생태계 기능 상실 은 토양생물에게 매우 치명적이라고 할 수 있다. ${ }^{2)}$ 육상 환 경은 다양한 인간 활동의 배경이 되므로 활동 과정에서 다 양한 목적으로 사용되는 화학물질들이 토양 환경으로 누출 될 개연성이 존재한다. 화학물질을 취급하는 생산 시설이나 공장 등의 사업장들은 다양한 화학물질을 다량 취급하기 때 문에 사고 발생 시 큰 피해를 유발할 수 있는데, ${ }^{3)}$ 그 예로 국외뿐 아니라 국내에서도 이러한 화학 물질에 의한 사고가
여러 건 발생해왔으며, ${ }^{4-9)}$ 이로 인한 극심한 피해를 사전에 방지하고자 2015년 화학물질관리법이 개정된 바 있다. ${ }^{6,10,11)}$ 그러나 사전에 화학물질에 의한 사고를 방지하는 것뿐 아니 라 발생할 수 있는 사고를 대비하여 중요한 환경 매체인 육 상 환경을 화학 사고로부터 보호하고 관리할 수 있는 방안 이 필요하다.

이를 위하여 사전에 화학사고에 특별히 취약하다고 판단 되는 지역을 선별, 사전에 관리를 강화하여 치명적인 피해를 예방할 수 있는 취약성 평가(Vulnerability assessment)가 육상 생태계에서 수행될 필요성이 존재한다. 환경 분야에서는 주로 기후 변화 ${ }^{12-17)}$, 지하수 오염 ${ }^{18-20)}$, 산사태 ${ }^{21,22)}$, 침수 ${ }^{2324)}$, 태풍 ${ }^{25)}$, 홍수 $^{26)}$ 등에 대한 취약성 평가가 수행된 바 있으나 화학물질 또는 화학사고 등에 의한 특정 지역에 대한 취약성을 평가 하는 연구의 경우에는 화학물질을 취급하는 시설, 플랜트, 산업 단지 등이 존재하는 지역에 대하여 지리 정보 체계 
(Geographic Information System, GIS)기반의 지역적 취약성 을 평가한 연구들이 대부분이다. ${ }^{27-31)} \mathrm{GIS}$ 기반 취약성 평가 의 경우, 대상 지역의 공간 및 지리적 정보를 활용하여 특정 사건 및 사고에 대한 취약성을 평가하는 것으로, 기존 GIS 기반 취약성 평가들에서는 대상 지역의 지형이나 지질, 토 양 특성, 토지이용 특성 등을 활용하여 취약성 평가를 수행 하였다. 국외에서 토양 및 지하수에 대한 취약성 평가 목적 으로 널리 사용되는 GIS 기반의 모델은 WIN-PST(미국 농림청 자연자원보전국), SCI-GROW(미국 환경청), $\mathrm{CLERS(하와이}$ 주), PRZM-3, PELMO, PEARL, MACRO(유럽 국가) 등이 존재 한다.

현재까지의 연구에 따르면 화학사고 및 화학물질 누출 등 에 대한 생물종 특성 기반의 취약성 평가는 수행된 바가 없 는 것으로 확인되었다. 또한 육상 및 토양 환경에 대한 취약 성 평가 연구는 현재까지 토양 오염 등에 대한 가능성을 간 단한 지표로 판별하거나 단순한 자연현상들을 이론적으로 사용, 또는 모니터링 자료를 이용하여 모델링 기법을 사용하 는 등의 연구가 주로 수행되었다. ${ }^{32)}$ 그러나 단순히 토양 및 육상 매체만을 대상으로 하는 취약성 평가가 아닌 토양 내 생물 및 비생물적인 모든 요소에 대한 취약성을 평가하기 위해서는 GIS를 기반으로 한 대상 지역의 공간 및 지리적 정보뿐 아니라 서식 생물의 특성과 화학물질에 대한 민감도 등을 취약성 평가에 반영하는 과정이 반드시 필요하다.

본 연구는 화학사고에 대응하기 위한 피해산정 기술을 마 련하고 화학물질 안전에 대한 국가적 차원의 대응책을 수립 하며 화학사고로 인한 환경피해를 정확하게 진단, 환경적 손실을 줄이기 위한 국가사업인「화학사고 대응 환경기술개 발사업」내「화학사고 후 생태계오염 모니터링 및 생태영향 통합평가 기술 개발」 연구 과제의 일환으로 수행되었다. 본 연구의 선행 연구인「화학사고 대비 육상생태 취약성 평가 기법 개발 연구: (1) 목본류를 중심으로」3)에서는 화학사고 가 발생할 경우 육상 생태계에 서식하는 목본류(41종 교목 및 41종 관목)의 화학물질에 대한 노출 시나리오를 가정하 여 목본류 식물의 특성에 따른 화학물질에 대한 취약성 평 가를 우선적으로 수행하였다. 그 후속 연구인 본 연구에서 는 선행 연구와 동일하게 화학사고로 인해 화학물질 누출 등이 발생하여 토양 및 육상 환경이 화학물질에 노출되었을 경우를 대비, 화학물질에 특별히 취약한 지역을 우선적으로 선정하고 이로 인한 피해를 최소화하는 것을 목적으로 특정 지역에 서식하는 생물종들의 생활사 등의 특성을 반영하여 생태 서식종 중심의 육상 생태계 보호를 위한 취약성 평가 를 수행하고자 취약성 평가 기법을 제안하는 것을 목표로 하였다. 초본류 식물에 대한 취약성 평가를 위하여 사용되 는 범주 및 인자들을 국내 식물 특성에 대한 기존 데이터를 활용하여 우선적으로 선정, 대상 초본 식물의 특성을 조사 하여 배점체계를 통한 정량화를 시도하였다. 본 연구를 통
하여 육상 및 토양 생태계 내에서 화학사고 등이 발생하였 을 경우 특정 화학물질에 대한 생물종의 취약성을 평가하 여 이를 기반으로 실제 사고 발생 시 피해를 최소화하는 등 의 활용 방안을 제안하는 것이 본 논문의 목적이라고 할 수 있다.

\section{2. 자료 및 연구방법}

\section{1. 화학사고 대비물질에 대한 육상 생태계 취약성 평가의 개념}

본 연구에서는 기존에 수행되었던 목본류를 이용한 육상 생태계 취약성 평가 ${ }^{33)}$ 의 개념을 동일하게 적용하여 육상 생 태계에 서식하는 초본류의 생활 특성 기반 취약성 평가 기 반 작업을 수행하였다. 취약성 평가는 노출(exposure)과 복원 (recovery)의 범주(category)로 구성, 각 범주는 하위 특성(trait) 으로 구성하였으며 이 특성들을 취약성 인자(vulnerability indicator)로 명명하여 인자들을 정량적으로 배점, 최종적으 로 육상 생태계에 서식하는 초본류의 취약성을 정량화하는 것을 목표로 하였다. 다양한 취약성 인자들을 정량화 및 표 준화하기 위하여 취약성 인자 점수를 산출하고자 하였으며 각 인자의 배점을 0 에서 1 사이의 점수로 산출하였다(점수 가 0 에서 1 로 향할수록 더 취약함을 의미). 각 인자의 배점 을 산출한 후 이를 범주별로 평균값을 계산, 노출 범주와 회 복 범주의 평균값을 산출하는 과정을 통해 최종적인 취약성 지수를 산출하였다.

취약성 평가를 효과적으로 수행하기 위해서는 우선적으 로 생물의 생활 특성에 기반한 취약성 평가를 수행한 후, 화 학물질 및 화학사고의 영향을 추후 반영하여 각 생물종의 취약성을 평가할 필요성이 있다. 이러한 생물의 생활 특성 에 기반한 취약성 평가의 경우, 생물종의 고유한 취약성을 생태학적 특성 기반으로 조사하는 것으로, 본 기법에서는 기존 연구 ${ }^{33)}$ 에서 수행되었던 관속식물 중 목본류에 대한 취 약성평가의 후속 연구로 관속식물 중 초본류에 대한 노출 및 복원 특성을 조사하여 취약성 평가를 수행하고자 하였 다. 이를 위하여 국내 서식 육상 생물종 내 관속식물의 전체 목록을 조사하고 이 중 가용한 특성이 알려진 초본 식물의 일부를 취약성 평가에 활용하고자 하였다. 「국가 생물종 목 록(국립생물자원관)」 ${ }^{34)}$ 을 바탕으로 관속식물류 4,518종을 확인하였고「전국 자연환경 조사 데이터북 -1 . 한국의 식 물(국립생태원)」 ${ }^{35)}$ 을 기준, 전국 시도별 생물상 현황에서 최 소 227 종 최대 1,729 종의 식물상을 확인하였다. 이를 기반 으로 하여 초본류 식물을 선별, 취약성 평가에 활용하였다.

초본류 식물 선별 과정의 경우, 목본류 식물에 대한 조사 와 유사하게 수행되었다. 3 개 식물문 및 8 개 강 아래의 74 개 목(또는 173 개 과)에 대하여 전국의 17 개 시·도 분류에 따라 범용성을 위하여 14-16개 이상 지역에서 분포하는 식 물을 선별하였으며 목분류 식물 선별 과정과 동일하게 생물 
다양성을 고려, 대상 생물 종이 국내에서 널리 분포하지 않 더라도 다양한 생물 종의 취약성을 조사하기 위한 목적으로 대상 식물의 목(order)을 기준, 가장 지역적으로 많이 분포 하는 식물을 하나씩은 포함할 수 있도록 하였다. 이러한 과 정에서 전국자연환경조사 데이터북에서 제시하고 있는 전 국 시·도별 식물 출현 현황에 따라, 2개 식물문(양치식물문, 현화식물문=피자식물문=속씨식물문) 내 6개 강(석송강, 솔 잎난강, 속새강, 고사리강(이상 양치식물문), 목련강, 백합강 (이상 현화식물문))에 대한 자료 수집 과정을 완료하였다. 초본류 식물의 경우에는 목본류 식물과 달리 일부 양치식물 문을 제외한 대부분의 식물이 현화식물문 $(=$ 피자식물문 $=$ 속 씨식물문)으로 확인되었다.

생물종을 선별과정 후, 국가 생물종 목록을 확인하여 취약성 평 가에 필요한 초본 특성 자료를 취합하였으며, 「새로운 한국식물도 감 ${ }^{36)}$, 「국가생물종 지식정보시스템」(http://www.nature.go.kr/) $)^{37)}$, 「식별이 쉬운 나무 도감」 ${ }^{38)}$ 등의 자료를 활용하였다. 최종적 으로 초본 215 종을 취약성 평가 대상 식물종으로 선정하였다

\section{(Table 1).}

\section{2. 초본류에 대한 육상 생태계 취약성 평가 적용 예시}

215종의 선별된 초본을 대상으로 취약성 인자를 선정하였다. 노출(exposure)범주의 경우 높이(height), 생활사(life cycle), 경 제적 가치(economic value)의 세 가지 취약성 인자를 선정하 였는데, 목본의 취약성 평가 연구에서 사용되었던 직경 (diameter) 및 잎의 형태(leaf) 인자의 경우 가용한 자료 부재 로 사용하지 않았다. 노출 범주는 선행연구인 목본 취약성평 가 연구에서 설명하였듯이 화학사고 발생 시 식물이 화학물 질에 노출될 경우 식물 특성에 따른 피해 정도의 차이를 유발 할 것으로 예상되는 인자 및 노출로 인해 피해가 발생할 것으 로 예상되는 인자를 선정하였으며 「새로운 한국식물도감 ${ }^{36)}$, $\ulcorner$ 국가생물종 지식정보시스템」(http://www.nature.go.kr//37), 「식별이 쉬운 나무 도감 ${ }^{38)}$ 에서 가용한 자료를 활용하였다. 세 가지 노출 인자 선정 시, 초본의 높이와 생활사의 경우에 는 화학사고 발생 시 식물이 화학물질에 노출되는 환경조건 및 기간과 직접적인 관계가 있으며, 경제적 가치의 경우에 는 노출로 인한 직접적인 피해가 발생하므로 노출 범주에 포함되었다. 초본 식물의 회복(recovery)범주의 경우, 식물의 성별(sexes), 개화-결실 기간(florescence and fruition), 분포 (distribution)의 목본류 연구와 동일한 세 가지 취약성 인자를 선정하였으며(Table 2) 이는 선행연구와 마찬가지로 화학사 고 발생 시, 화학물질에 노출된 초본의 생식 및 후세대 개체 의 특성 및 개체 수에 영향을 미칠 수 있을 것으로 예상되는 인자를 선정한 것으로, 동일하게 「새로운 한국식물도감 ${ }^{36)}$, 「국가생물종 지식정보시스템」(http://www.nature.go.kr//37), $\left\ulcorner\right.$ 식별이 쉬운 나무 도감 ${ }^{38)}$ 에서 가용한 자료를 활용하고자 하였다. 세 가지 회복 인자 선정 시, 초본 식물의 성별에 따
라 단일 개체에 의한 생식이 불가능하거나 개화-결실기간이 길어 화학사고가 발생한 환경에서 생식이 용이하지 않거나, 식물의 분포 지역이 한정적이라 화학사고로 인한 절멸 가능 성이 높은 등의 군집 회복에 치명적일 수 있다는 특성이 있 으므로 이러한 인자들이 회복 범주에 포함되었다. 이에 따라 노출 및 회복 범주에 속하는 각 취약성 인자에 대한 자료조 사를 수행, 각 특성에 적합하게 배점체계를 0 에서 1 사이의 점수로 배점하도록 하였다. 배점구간 설정의 경우, 확보된 특성 자료들의 최솟값 및 최댓값을 고려하여 데이터가 최대 한 정규분포를 따를 수 있도록 설정하였으며 이는 추후 타 생물종에 대한 취약성 평가 수행 시 개선이 가능하다.

노출(exposure) 인자 중 높이(height)의 경우, 「새로운 한국식물 도감 ${ }^{36)}$ 및 국가생물종지식정보시스템(http://www.nature.go.kr/) ${ }^{37)}$ 을 참고하여 얻은 정보를 각 초본 별로 수집하고 배점 구간을 $\leq 10,10<\mathrm{x} \leq 30,30<\mathrm{x} \leq 50,50<\mathrm{x} \leq 100,>100$ $\mathrm{cm}$ 로 설정, 배점을 각각 $1,0.8,0.6,0.4,0.2$ 로 설정하였다. 이는 높이가 낮은 초본의 경우 화학물질 및 화학사고로 인한 토양 오염에 더 취약할 것으로 가정한 배점체계이다(화학물 질이 지반 및 토양 환경 중으로 누출이 되었어도 화학물질의 특성에 따라 대기 중으로의 휘발 및 확산에 의해 2차 피해가 발생할 수 있으며 이는 수고가 높은 식물에 추가적인 영향을 줄 수 있다는 가능성이 있으나 본 연구에서는 고려되지 않았 다). 생활사(life cycle)의 경우, 「새로운 한국식물도감」 ${ }^{36)}$ 을 참고하여 얻은 생활사에 대한 정보를 각 초본별로 수집하고 다년초에 대한 배점은 0.5 , 일년초 및 월년초에 대한 배점을 1 로 하였다. 이는 생활사가 짧을수록 일정 기간의 화학물질 노출이 상대적 장기노출로 해석될 수 있기 때문이다. 마지막 으로 경제적 가치(economic value)의 경우, 「새로운 한국식물 도감 ${ }^{36)}$ 을 참고하여 얻은 초본 식물의 용도 정보를 수집하고 0 개, 1 개, 2 개, 3 개 이상으로 설정하여 배점을 각각 $0.25,0.5$, $0.75,1$ 로 하여 용도가 다양한 식물일수록 경제적으로 더 취 약한 것으로 가정하였다. 초본 식물의 경우, 식용, 약용, 염료, 섬유 등의 다양한 용도로 생활에서 활용되는 경우가 많은데, 경제적 가치의 경우, 노출 인자와의 상관성은 높지 않으나 화학물질에 노출될 경우 이로 인해 초본 식물의 기능과 가치 가 하락하고 경제적 손실을 유발할 수 있다는 점에서 노출 인자에 포함하였다.

회복(recovery) 인자 중 성별(sexes)의 경우, 목본류 식물 과 동일한 배점체계를 채택하였다. 「새로운 한국식물도감」 ${ }^{36)}$, 국가생물종지식정보시스템(http://www.nature.go.kr/) $)^{37)}$ 및 기 타 자료를 참고하여 얻은 성별의 정보를 각 초본 식물 별로 수집하고 자웅동체에 대한 배점을 0.5 , 자웅이체에 대한 배점을 1 로 하였다. 이는 식물이 자웅이체일 경우, 자 웅동체인 식물보다 생식에 어려움이 발생할 수 있을 것으 로 가정하였다. 개화-결실 기간(florescence and fruition)의 경우, 「새로운 한국식물도감」36) 및 국가생물종지식정보시스템 
Table 1. List of 215 herbs selected for vulnerability assessment.

\begin{tabular}{|c|c|c|c|}
\hline No. & Herbs & No. & Herbs \\
\hline 1 & Selaginella tamariscina & 60 & Viola rossii \\
\hline 2 & Isoetes coreana & 61 & Viola selkirkii \\
\hline 3 & Botrychium ternatum & 62 & Viola verecunda \\
\hline 4 & Psilotum nudum & 63 & Capsella bursa-pastoris \\
\hline 5 & Equisetum arvense & 64 & Cardamine fallax \\
\hline 6 & Osmunda japonica & 65 & Cardamine flexuosa \\
\hline 7 & Hymenophyllum polyanthos & 66 & Cardamine leucantha \\
\hline 8 & Dicranopteris linearis & 67 & Draba nemorosa \\
\hline 9 & Lygodium japonicum & 68 & Lepidium apetalum \\
\hline 10 & Plagiogyria euphlebia & 69 & Rorippa indica \\
\hline 11 & Pteridium aquilinum & 70 & Pyrola japonica \\
\hline 12 & Asplenium incisum & 71 & Androsace umbellata \\
\hline 13 & Athyrium yokoscense & 72 & Lysimachia clethroides \\
\hline 14 & Dryopteris chinensis & 73 & Sedum kamtschaticum \\
\hline 15 & Dryopteris saxifraga & 74 & Sedum sarmentosum \\
\hline 16 & Dryopteris varia & 75 & Agrimonia pilosa \\
\hline 17 & Polystichum tripteron & 76 & Geum japonicum \\
\hline 18 & Chloranthus japonicus & 77 & Potentilla anemonifolia \\
\hline 19 & Asarum sieboldii & 78 & Potentilla dickinsii \\
\hline 20 & Hepatica asiatica & 79 & Potentilla fragarioides \\
\hline 21 & Ranunculus chinensis & 80 & Potentilla freyniana \\
\hline 22 & Ranunculus japonicus & 81 & Sanguisorba officinalis \\
\hline 23 & Chelidonium majus & 82 & Chamaecrista nomame \\
\hline 24 & Corydalis remota & 83 & Desmodium podocarpum \\
\hline 25 & Corydalis speciosa & 84 & Glycine soja \\
\hline 26 & Humulus japonicus & 85 & Kummerowia striata \\
\hline 27 & Boehmeria tricuspis & 86 & Lespedeza cuneata \\
\hline 28 & Phytolacca americana & 87 & Sophora flavescens \\
\hline 29 & Chenopodium album & 88 & Trifolium repens \\
\hline 30 & Achyranthes japonica & 89 & Haloragis micrantha \\
\hline 31 & Arenaria serpyllifolia & 90 & Oenothera odorata \\
\hline 32 & Cerastium holosteoides & 91 & Thesium chinense \\
\hline 33 & Dianthus longicalyx & 92 & Acalypha australis \\
\hline 34 & Pseudostellaria heterophylla & 93 & Linum usitatissimum \\
\hline 35 & Pseudostellaria palibiniana & 94 & Polygala japonica \\
\hline 36 & Silene firma & 95 & Dictamnus dasycarpus \\
\hline 37 & Stellaria alsine & 96 & Oxalis corniculata \\
\hline 38 & Stellaria aquatica & 97 & Geranium thunbergii \\
\hline 39 & Stellaria media & 98 & Angelica decursiva \\
\hline 40 & Polygonumaviculare & 99 & Peucedanum terebinthaceum \\
\hline 41 & Polygonum filiforme & 100 & Torilis japonica \\
\hline 42 & Polygonum lapathifolium & 101 & Gentiana zollgeri \\
\hline 43 & Polygonum longisetum & 102 & Metaplexis japonica \\
\hline 44 & Polygonum perfoliatum & 103 & Calystegia sepium \\
\hline 45 & Polygonum sagittatum & 104 & Trigonotis peduncularis \\
\hline 46 & Polygonum senticosum & 105 & Clerodendrum trichotomum \\
\hline 47 & Polygonum thunbergii & 106 & Phryma leptostachya \\
\hline 48 & Rumex acetosa & 107 & Agastache rugosa \\
\hline 49 & Rumex crispus & 108 & Ajuga multiflora \\
\hline 50 & Paeonia japonica & 109 & Clinopodium chinense \\
\hline 51 & Hypericum ascyron & 110 & Elsholtzia splendens \\
\hline 52 & Hypericum erectum & 111 & Isodon inflexus \\
\hline 53 & Corchoropsis tomentosa & 112 & Isodon japonicus \\
\hline 54 & Drosera rotundifolia & 113 & Lamium amplexicaule \\
\hline 55 & Viola acuminata & 114 & Leonurus japonicus \\
\hline 56 & Viola albida & 115 & Lycopus lucidus \\
\hline 57 & Viola japonica & 116 & Mosla dianthera \\
\hline 58 & Viola keiskei & 117 & Mosla punctulata \\
\hline 59 & Viola mandshurica & 118 & Scutellaria indica \\
\hline
\end{tabular}


Table 1. Continued

\begin{tabular}{|c|c|c|c|}
\hline No. & Herbs & No. & Herbs \\
\hline 119 & Scutellaria pekensis & 168 & Juncus effusus \\
\hline 120 & Plantago asiatica & 169 & Luzula capitata \\
\hline 121 & Mazus pumilus & 170 & Carex humilis \\
\hline 122 & Melampyrum roseum & 171 & Carex lanceolata \\
\hline 123 & Veronica arvensis & 172 & Carex leiorhyncha \\
\hline 124 & Veronica persica & 173 & Carex siderosticta \\
\hline 125 & Justicia procumbens & 174 & Cyperus amuricus \\
\hline 126 & Adenophora triphylla & 175 & Cyperus iria \\
\hline 127 & Galium spurium & 176 & Agropyron ciliare \\
\hline 128 & Galium verum & 177 & Agropyron tsukushiense \\
\hline 129 & Rubia akane & 178 & Alopecurus aequalis \\
\hline 130 & Patrinia scabiosifolia & 179 & Arundinella hirta \\
\hline 131 & Valeriana fauriei & 180 & Calamagrostis arundinacea \\
\hline 132 & Ambrosia artemisiifolia & 181 & Cymbopogon tortilis \\
\hline 133 & Artemisia capillaris & 182 & Dactylis glomerata \\
\hline 134 & Artemisia japonica & 183 & Digitaria sanguinalis \\
\hline 135 & Artemisia keiskeana & 184 & Echinochloa crusgalli \\
\hline 136 & Artemisia princeps & 185 & Eragrostis ferruginea \\
\hline 137 & Aster ageratoides & 186 & Eriochloa villosa \\
\hline 138 & Aster scaber & 187 & Festuca ovina \\
\hline 139 & Aster yomena & 188 & Miscanthus sinensis \\
\hline 140 & Atractylodes ovata & 189 & Muhlenbergia japonica \\
\hline 141 & Bidens bipinnata & 190 & Oplismenus undulatifolius \\
\hline 142 & Bidens frondosa & 191 & Paspalum thunbergii \\
\hline 143 & Cirsium japonicum & 192 & Pennisetum alopecuroides \\
\hline 144 & Conyza bonariensis & 193 & Phragmites communis \\
\hline 145 & Conyza canadensis & 194 & Poa sphondylodes \\
\hline 146 & Cosmos bipinnatus & 195 & Setaria glauca \\
\hline 147 & Crepidiastrum sonchifolium & 196 & Setaria viridis \\
\hline 148 & Dendranthema boreale & 197 & Spodiopogon sibiricus \\
\hline 149 & Dendranthema zawadskii & 198 & Themeda triandra \\
\hline 150 & Erigeron annuus & 199 & Zingiber mioga \\
\hline 151 & Eupatorium japonicum & 200 & Allium sacculiferum \\
\hline 152 & Eupatorium lindleyanum & 201 & Asparagus schoberioides \\
\hline 153 & Hemistepta lyrata & 202 & Convallaria keiskei \\
\hline 154 & Ixeridium dentatum & 203 & Disporum smilacinum \\
\hline 155 & Lactuca indica & 204 & Hemerocallis fulva \\
\hline 156 & Leibnitzia anandria & 205 & Hosta longipes \\
\hline 157 & Petasites japonicus & 206 & Lilium amabile \\
\hline 158 & Solidago virgaurea & 207 & Lilium tsingtauense \\
\hline 159 & Sonchus oleraceus & 208 & Liriope platyphylla \\
\hline 160 & Taraxacum coreanum & 209 & Polygonatum odoratum \\
\hline 161 & Taraxacum officinale & 210 & Scilla scilloides \\
\hline 162 & Tephroseris kirilowii & 211 & Iris rossii \\
\hline 163 & Youngia japonica & 212 & Smilax nipponica \\
\hline 164 & Taraxacum platycarpum & 213 & Smilax riparia \\
\hline 165 & Arisaema peninsulae & 214 & Cephalanthera longibracteata \\
\hline 166 & Commelina communis & 215 & Spiranthes sinensis \\
\hline 167 & Eriocaulon robustius & & \\
\hline
\end{tabular}

Table 2. Selection of vulnerability assessment factors for 215 species of herbs.

\section{Category}

Vulnerability indicators

\section{Exposure}

Height

Life cycle

Economic value

\section{Recovery}

Sexes

Florescence and fruition Distribution 
(http://www.nature.go.kr/) $)^{37)}$ 을 참고하여 얻은 개화-결실기 정 보를 각 식물별로 수집하고 구간을 $\leq 2,2<\mathrm{x} \leq 3,3<$ $\mathrm{x} \leq 4,>4$ 개월로 설정하여 배점을 각각 $0.25,0.5,0.75,1$ 로 하였다. 이는 개화-결실 기간이 길수록 화학사고 발생 후 군집 회복력이 낮기 때문에 더 취약할 것으로 사료되기 때 문이다. 마지막으로 분포(distribution)의 경우,「전국자연환 경조사데이터북 본문 1 권(한국의 식물)」 ${ }^{35)}$ 을 참고하여 얻은 분포 정보를 각 초본 식물별로 수집하고 구간을 1-3, 4-7,
$8-11,12-15,16-17$ 개 시, 도로 설정하여 배점을 각각 $1,0.8$, $0.6,0.4,0.2$ 로 하였다. 이는 더 좁은 지역에 한정적으로 분포 할수록 화학사고 발생 후 회복력이 낮아 취약할 것이라고 가 정하였다. 종합적으로 노출(exposure)범주 내 특성 점수들의 평균값의 $1 / 2$ 및 회복(recovery) 범주 내 특성 점수들의 평균 값의 $1 / 2$ 를 합산하여 215 종 초본의 취약성 지수를 산출하였 으며 이를 바탕으로 초본들의 취약성 순위를 결정하였다

(Table 3).

Table 3. Results of vulnerability score calculation for 215 herbs.

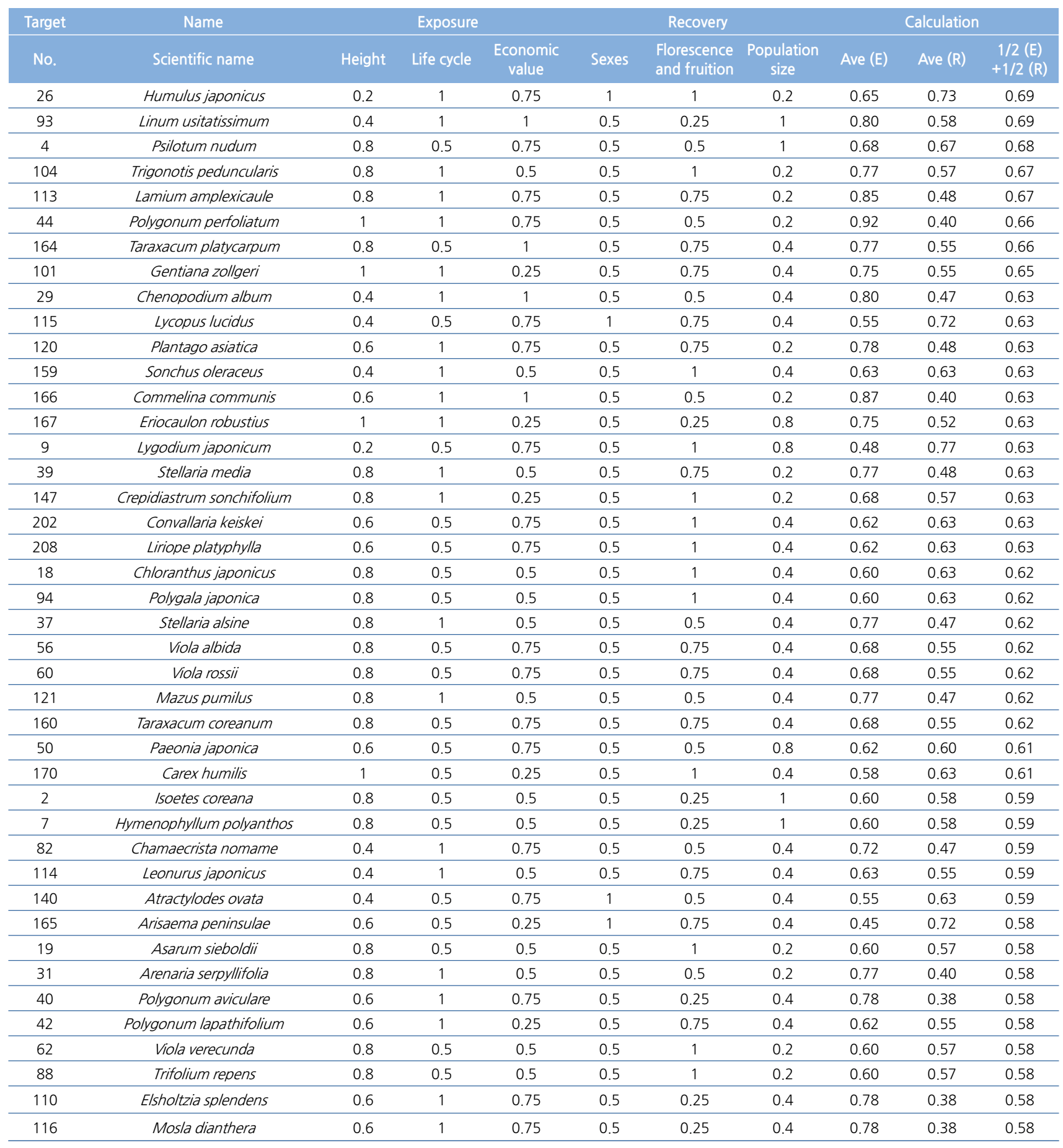


Table 3. Continued

\begin{tabular}{|c|c|c|c|c|c|c|c|c|c|c|}
\hline \multirow{2}{*}{$\begin{array}{c}\text { Target } \\
\text { No. }\end{array}$} & \multirow{2}{*}{$\begin{array}{c}\text { Name } \\
\text { Scientific name }\end{array}$} & \multicolumn{3}{|c|}{ Exposure } & \multicolumn{3}{|c|}{ Recovery } & \multicolumn{3}{|c|}{ Calculation } \\
\hline & & Height & Life cycle & $\begin{array}{c}\text { Economic } \\
\text { value }\end{array}$ & Sexes & $\begin{array}{l}\text { Florescence } \\
\text { and fruition }\end{array}$ & $\begin{array}{l}\text { Population } \\
\text { size }\end{array}$ & Ave (E) & Ave (R) & $\begin{array}{c}1 / 2(\mathrm{E}) \\
+1 / 2(\mathrm{R})\end{array}$ \\
\hline 156 & Leibnitzia anandria & 0.8 & 0.5 & 0.5 & 0.5 & 1 & 0.2 & 0.60 & 0.57 & 0.58 \\
\hline 32 & Cerastium holosteoides & 0.8 & 1 & 0.5 & 0.5 & 0.25 & 0.4 & 0.77 & 0.38 & 0.58 \\
\hline 35 & Pseudostellaria palibiniana & 0.8 & 0.5 & 0.5 & 0.5 & 0.75 & 0.4 & 0.60 & 0.55 & 0.58 \\
\hline 64 & Cardamine fallax & 0.8 & 1 & 0.5 & 0.5 & 0.25 & 0.4 & 0.77 & 0.38 & 0.58 \\
\hline 161 & Taraxacum officinale & 0.8 & 0.5 & 0.75 & 0.5 & 0.5 & 0.4 & 0.68 & 0.47 & 0.58 \\
\hline 20 & Hepatica asiatica & 1 & 0.5 & 0.75 & 0.5 & 0.25 & 0.4 & 0.75 & 0.38 & 0.57 \\
\hline 71 & Androsace umbellata & 1 & 1 & 0.25 & 0.5 & 0.25 & 0.4 & 0.75 & 0.38 & 0.57 \\
\hline 10 & Plagiogyria euphlebia & 0.6 & 0.5 & 0.5 & 0.5 & 0.25 & 1 & 0.53 & 0.58 & 0.56 \\
\hline 43 & Polygonum longisetum & 0.4 & 1 & 0.25 & 0.5 & 1 & 0.2 & 0.55 & 0.57 & 0.56 \\
\hline 54 & Drosera rotundifolia & 0.8 & 0.5 & 0.5 & 0.5 & 0.25 & 0.8 & 0.60 & 0.52 & 0.56 \\
\hline 68 & Lepidium apetalum & 0.4 & 1 & 0.5 & 0.5 & 0.75 & 0.2 & 0.63 & 0.48 & 0.56 \\
\hline 146 & Cosmos bipinnatus & 0.2 & 1 & 0.5 & 0.5 & 0.75 & 0.4 & 0.57 & 0.55 & 0.56 \\
\hline 155 & Lactuca indica & 0.2 & 1 & 0.5 & 0.5 & 0.75 & 0.4 & 0.57 & 0.55 & 0.56 \\
\hline 213 & Smilax riparia & 0.2 & 0.5 & 0.5 & 1 & 0.75 & 0.4 & 0.40 & 0.72 & 0.56 \\
\hline 100 & Torilis japonica & 0.4 & 1 & 0.75 & 0.5 & 0.25 & 0.4 & 0.72 & 0.38 & 0.55 \\
\hline 127 & Galium spurium & 0.4 & 1 & 0.75 & 0.5 & 0.25 & 0.4 & 0.72 & 0.38 & 0.55 \\
\hline 141 & Bidens bipinnata & 0.4 & 1 & 0.75 & 0.5 & 0.25 & 0.4 & 0.72 & 0.38 & 0.55 \\
\hline 178 & Alopecurus aequalis & 0.6 & 1 & 0.75 & 0.5 & 0.25 & 0.2 & 0.78 & 0.32 & 0.55 \\
\hline 48 & Rumex acetosa & 0.4 & 0.5 & 0.75 & 0.5 & 0.75 & 0.4 & 0.55 & 0.55 & 0.55 \\
\hline 51 & Hypericum ascyron & 0.4 & 0.5 & 0.75 & 0.5 & 0.75 & 0.4 & 0.55 & 0.55 & 0.55 \\
\hline 72 & Lysimachia clethroides & 0.4 & 0.5 & 0.75 & 0.5 & 0.75 & 0.4 & 0.55 & 0.55 & 0.55 \\
\hline 81 & Sanguisorba officinalis & 0.4 & 0.5 & 0.75 & 0.5 & 0.75 & 0.4 & 0.55 & 0.55 & 0.55 \\
\hline 131 & Valeriana fauriei & 0.4 & 0.5 & 1 & 0.5 & 0.5 & 0.4 & 0.63 & 0.47 & 0.55 \\
\hline 174 & Cyperus amuricus & 0.4 & 1 & 0.5 & 0.5 & 0.5 & 0.4 & 0.63 & 0.47 & 0.55 \\
\hline 206 & Lilium amabile & 0.4 & 0.5 & 0.75 & 0.5 & 0.75 & 0.4 & 0.55 & 0.55 & 0.55 \\
\hline 23 & Chelidonium majus & 0.6 & 1 & 0.25 & 0.5 & 0.5 & 0.4 & 0.62 & 0.47 & 0.54 \\
\hline 34 & Pseudostellaria heterophylla & 0.8 & 0.5 & 0.75 & 0.5 & 0.5 & 0.2 & 0.68 & 0.40 & 0.54 \\
\hline 49 & Rumex crispus & 0.6 & 0.5 & 0.75 & 0.5 & 0.5 & 0.4 & 0.62 & 0.47 & 0.54 \\
\hline 59 & Viola mandshurica & 0.8 & 0.5 & 0.75 & 0.5 & 0.5 & 0.2 & 0.68 & 0.40 & 0.54 \\
\hline 65 & Cardamine flexuosa & 0.8 & 1 & 0.5 & 0.5 & 0.25 & 0.2 & 0.77 & 0.32 & 0.54 \\
\hline 66 & Cardamine leucantha & 0.6 & 0.5 & 0.5 & 0.5 & 0.75 & 0.4 & 0.53 & 0.55 & 0.54 \\
\hline 67 & Draba nemorosa & 0.8 & 1 & 0.5 & 0.5 & 0.25 & 0.2 & 0.77 & 0.32 & 0.54 \\
\hline 76 & Geum japonicum & 0.6 & 0.5 & 0.75 & 0.5 & 0.5 & 0.4 & 0.62 & 0.47 & 0.54 \\
\hline 125 & Justicia procumbens & 0.8 & 1 & 0.5 & 0.5 & 0.25 & 0.2 & 0.77 & 0.32 & 0.54 \\
\hline 139 & Aster yomena & 0.6 & 0.5 & 0.5 & 0.5 & 0.75 & 0.4 & 0.53 & 0.55 & 0.54 \\
\hline 157 & Petasites japonicus & 0.6 & 0.5 & 0.5 & 1 & 0.25 & 0.4 & 0.53 & 0.55 & 0.54 \\
\hline 190 & Oplismenus undulatifolius & 0.8 & 1 & 0.5 & 0.5 & 0.25 & 0.2 & 0.77 & 0.32 & 0.54 \\
\hline 8 & Dicranopteris linearis & 0.4 & 0.5 & 0.5 & 0.5 & 0.5 & 0.8 & 0.47 & 0.60 & 0.53 \\
\hline 55 & Viola acuminata & 0.8 & 0.5 & 0.5 & 0.5 & 0.5 & 0.4 & 0.60 & 0.47 & 0.53 \\
\hline 70 & Pyrola japonica & 0.8 & 0.5 & 0.5 & 0.5 & 0.5 & 0.4 & 0.60 & 0.47 & 0.53 \\
\hline 78 & Potentilla dickinsii & 0.8 & 0.5 & 0.5 & 0.5 & 0.5 & 0.4 & 0.60 & 0.47 & 0.53 \\
\hline 91 & Thesium chinense & 0.8 & 0.5 & 0.5 & 0.5 & 0.5 & 0.4 & 0.60 & 0.47 & 0.53 \\
\hline 96 & Oxalis corniculata & 0.8 & 0.5 & 0.5 & 0.5 & 0.5 & 0.4 & 0.60 & 0.47 & 0.53 \\
\hline 108 & Ajuga multiflora & 0.8 & 0.5 & 0.5 & 0.5 & 0.5 & 0.4 & 0.60 & 0.47 & 0.53 \\
\hline 118 & Scutellaria indica & 0.8 & 0.5 & 0.5 & 0.5 & 0.5 & 0.4 & 0.60 & 0.47 & 0.53 \\
\hline 1 & Selaginella tamariscina & 0.8 & 0.5 & 0.75 & 0.5 & 0.25 & 0.4 & 0.68 & 0.38 & 0.53 \\
\hline 85 & Kummerowia striata & 0.8 & 1 & 0.25 & 0.5 & 0.25 & 0.4 & 0.68 & 0.38 & 0.53 \\
\hline 123 & Veronica arvensis & 0.8 & 1 & 0.25 & 0.5 & 0.25 & 0.4 & 0.68 & 0.38 & 0.53 \\
\hline 124 & Veronica persica & 0.8 & 1 & 0.25 & 0.5 & 0.25 & 0.4 & 0.68 & 0.38 & 0.53 \\
\hline 58 & Viola keiskei & 1 & 0.5 & 0.25 & 0.5 & 0.5 & 0.4 & 0.58 & 0.47 & 0.53 \\
\hline 61 & Viola selkirkii & 1 & 0.5 & 0.25 & 0.5 & 0.5 & 0.4 & 0.58 & 0.47 & 0.53 \\
\hline 199 & Zingiber mioga & 0.6 & 0.5 & 0.5 & 0.5 & 0.25 & 0.8 & 0.53 & 0.52 & 0.53 \\
\hline 47 & Polygonum thunbergii & 0.4 & 1 & 0.5 & 0.5 & 0.5 & 0.2 & 0.63 & 0.40 & 0.52 \\
\hline 150 & Erigeron annuus & 0.4 & 1 & 0.5 & 0.5 & 0.5 & 0.2 & 0.63 & 0.40 & 0.52 \\
\hline
\end{tabular}


Table 3. Continued

\begin{tabular}{|c|c|c|c|c|c|c|c|c|c|c|}
\hline \multirow{2}{*}{$\begin{array}{c}\text { Target } \\
\text { No. }\end{array}$} & \multirow{2}{*}{$\begin{array}{c}\text { Name } \\
\text { Scientific name }\end{array}$} & \multicolumn{3}{|c|}{ Exposure } & \multicolumn{3}{|c|}{ Recovery } & \multicolumn{3}{|c|}{ Calculation } \\
\hline & & Height & Life cycle & $\begin{array}{c}\text { Economic } \\
\text { value }\end{array}$ & Sexes & $\begin{array}{l}\text { Florescence } \\
\text { and fruition }\end{array}$ & $\begin{array}{l}\text { Population } \\
\text { size }\end{array}$ & Ave (E) & Ave (R) & $\begin{array}{c}1 / 2(\mathrm{E}) \\
+1 / 2(\mathrm{R})\end{array}$ \\
\hline 195 & Setaria glauca & 0.4 & 1 & 0.5 & 0.5 & 0.5 & 0.2 & 0.63 & 0.40 & 0.52 \\
\hline 209 & Polygonatum odoratum & 0.4 & 0.5 & 0.75 & 0.5 & 0.75 & 0.2 & 0.55 & 0.48 & 0.52 \\
\hline 6 & Osmunda japonica & 0.4 & 0.5 & 1 & 0.5 & 0.25 & 0.4 & 0.63 & 0.38 & 0.51 \\
\hline 33 & Dianthus longicalyx & 0.4 & 0.5 & 0.75 & 0.5 & 0.5 & 0.4 & 0.55 & 0.47 & 0.51 \\
\hline 38 & Stellaria aquatica & 0.6 & 1 & 0.5 & 0.5 & 0.25 & 0.2 & 0.70 & 0.32 & 0.51 \\
\hline 45 & Polygonum sagittatum & 0.4 & 1 & 0.25 & 0.5 & 0.5 & 0.4 & 0.55 & 0.47 & 0.51 \\
\hline 52 & Hypericum erectum & 0.4 & 0.5 & 0.75 & 0.5 & 0.5 & 0.4 & 0.55 & 0.47 & 0.51 \\
\hline 63 & Capsella bursa-pastoris & 0.6 & 1 & 0.5 & 0.5 & 0.25 & 0.2 & 0.70 & 0.32 & 0.51 \\
\hline 92 & Acalypha australis & 0.6 & 1 & 0.5 & 0.5 & 0.25 & 0.2 & 0.70 & 0.32 & 0.51 \\
\hline 106 & Phryma leptostachya & 0.4 & 0.5 & 0.75 & 0.5 & 0.5 & 0.4 & 0.55 & 0.47 & 0.51 \\
\hline 153 & Hemistepta lyrata & 0.4 & 1 & 0.5 & 0.5 & 0.25 & 0.4 & 0.63 & 0.38 & 0.51 \\
\hline 163 & Youngia japonica & 0.4 & 1 & 0.5 & 0.5 & 0.25 & 0.4 & 0.63 & 0.38 & 0.51 \\
\hline 201 & Asparagus schoberioides & 0.4 & 0.5 & 0.5 & 1 & 0.25 & 0.4 & 0.47 & 0.55 & 0.51 \\
\hline 203 & Disporum smilacinum & 0.6 & 0.5 & 0.75 & 0.5 & 0.5 & 0.2 & 0.62 & 0.40 & 0.51 \\
\hline 13 & Athyrium yokoscense & 0.6 & 0.5 & 0.5 & 0.5 & 0.5 & 0.4 & 0.53 & 0.47 & 0.50 \\
\hline 15 & Dryopteris saxifraga & 0.6 & 0.5 & 0.5 & 0.5 & 0.5 & 0.4 & 0.53 & 0.47 & 0.50 \\
\hline 24 & Corydalis remota & 0.8 & 0.5 & 0.5 & 0.5 & 0.5 & 0.2 & 0.60 & 0.40 & 0.50 \\
\hline 25 & Corydalis speciosa & 0.6 & 1 & 0.25 & 0.5 & 0.25 & 0.4 & 0.62 & 0.38 & 0.50 \\
\hline 109 & Clinopodium chinense & 0.6 & 0.5 & 0.75 & 0.5 & 0.25 & 0.4 & 0.62 & 0.38 & 0.50 \\
\hline 144 & Conyza bonariensis & 0.6 & 1 & 0.25 & 0.5 & 0.25 & 0.4 & 0.62 & 0.38 & 0.50 \\
\hline 162 & Tephroseris kirilowii & 0.6 & 0.5 & 0.5 & 0.5 & 0.5 & 0.4 & 0.53 & 0.47 & 0.50 \\
\hline 169 & Luzula capitata & 0.8 & 0.5 & 0.5 & 0.5 & 0.5 & 0.2 & 0.60 & 0.40 & 0.50 \\
\hline 173 & Carex siderosticta & 0.8 & 0.5 & 0.25 & 0.5 & 0.75 & 0.2 & 0.52 & 0.48 & 0.50 \\
\hline 175 & Cyperus iria & 0.6 & 1 & 0.25 & 0.5 & 0.25 & 0.4 & 0.62 & 0.38 & 0.50 \\
\hline 211 & Iris rossii & 0.8 & 0.5 & 0.5 & 0.5 & 0.5 & 0.2 & 0.60 & 0.40 & 0.50 \\
\hline 215 & Spiranthes sinensis & 0.6 & 0.5 & 0.5 & 0.5 & 0.5 & 0.4 & 0.53 & 0.47 & 0.50 \\
\hline 119 & Scutellaria pekensis & 0.8 & 0.5 & 0.25 & 0.5 & 0.5 & 0.4 & 0.52 & 0.47 & 0.49 \\
\hline 73 & Sedum kamtschaticum & 0.8 & 0.5 & 0.5 & 0.5 & 0.25 & 0.4 & 0.60 & 0.38 & 0.49 \\
\hline 74 & Sedum sarmentosum & 0.8 & 0.5 & 0.5 & 0.5 & 0.25 & 0.4 & 0.60 & 0.38 & 0.49 \\
\hline 89 & Haloragis micrantha & 0.8 & 0.5 & 0.25 & 0.5 & 0.25 & 0.6 & 0.52 & 0.45 & 0.48 \\
\hline 28 & Phytolacca americana & 0.2 & 0.5 & 0.75 & 0.5 & 0.75 & 0.2 & 0.48 & 0.48 & 0.48 \\
\hline 22 & Ranunculus japonicus & 0.4 & 0.5 & 0.75 & 0.5 & 0.5 & 0.2 & 0.55 & 0.40 & 0.48 \\
\hline 84 & Glycine soja & 0.2 & 1 & 0.5 & 0.5 & 0.25 & 0.4 & 0.57 & 0.38 & 0.48 \\
\hline 102 & Metaplexis japonica & 0.2 & 0.5 & 0.75 & 0.5 & 0.5 & 0.4 & 0.48 & 0.47 & 0.48 \\
\hline 103 & Calystegia sepium & 0.2 & 0.5 & 0.5 & 0.5 & 0.75 & 0.4 & 0.40 & 0.55 & 0.48 \\
\hline 105 & Clerodendrum trichotomum & 0.2 & 0.5 & 1 & 0.5 & 0.25 & 0.4 & 0.57 & 0.38 & 0.48 \\
\hline 111 & Isodon inflexus & 0.4 & 0.5 & 0.5 & 0.5 & 0.75 & 0.2 & 0.47 & 0.48 & 0.48 \\
\hline 117 & Mosla punctulata & 0.4 & 1 & 0.5 & 0.5 & 0.25 & 0.2 & 0.63 & 0.32 & 0.48 \\
\hline 129 & Rubia akane & 0.4 & 0.5 & 1 & 0.5 & 0.25 & 0.2 & 0.63 & 0.32 & 0.48 \\
\hline 143 & Cirsium japonicum & 0.4 & 0.5 & 0.75 & 0.5 & 0.5 & 0.2 & 0.55 & 0.40 & 0.48 \\
\hline 145 & Conyza canadensis & 0.4 & 1 & 0.5 & 0.5 & 0.25 & 0.2 & 0.63 & 0.32 & 0.48 \\
\hline 148 & Dendranthema boreale & 0.2 & 0.5 & 1 & 0.5 & 0.25 & 0.4 & 0.57 & 0.38 & 0.48 \\
\hline 149 & Dendranthema zawadskii & 0.4 & 0.5 & 0.75 & 0.5 & 0.5 & 0.2 & 0.55 & 0.40 & 0.48 \\
\hline 158 & Solidago virgaurea & 0.4 & 0.5 & 0.5 & 0.5 & 0.75 & 0.2 & 0.47 & 0.48 & 0.48 \\
\hline 168 & Juncus effusus & 0.4 & 0.5 & 0.75 & 0.5 & 0.5 & 0.2 & 0.55 & 0.40 & 0.48 \\
\hline 193 & Phragmites communis & 0.2 & 0.5 & 1 & 0.5 & 0.25 & 0.4 & 0.57 & 0.38 & 0.48 \\
\hline 212 & Smilax nipponica & 0.4 & 0.5 & 0.5 & 1 & 0.25 & 0.2 & 0.47 & 0.48 & 0.48 \\
\hline 3 & Botrychium ternatum & 0.6 & 0.5 & 0.75 & 0.5 & 0.25 & 0.2 & 0.62 & 0.32 & 0.47 \\
\hline 12 & Asplenium incisum & 0.6 & 0.5 & 0.5 & 0.5 & 0.5 & 0.2 & 0.53 & 0.40 & 0.47 \\
\hline 14 & Dryopteris chinensis & 0.6 & 0.5 & 0.5 & 0.5 & 0.5 & 0.2 & 0.53 & 0.40 & 0.47 \\
\hline 79 & Potentilla fragarioides & 0.6 & 0.5 & 0.5 & 0.5 & 0.5 & 0.2 & 0.53 & 0.40 & 0.47 \\
\hline 154 & Ixeridium dentatum & 0.6 & 0.5 & 0.75 & 0.5 & 0.25 & 0.2 & 0.62 & 0.32 & 0.47 \\
\hline 210 & Scilla scilloides & 0.6 & 0.5 & 0.5 & 0.5 & 0.5 & 0.2 & 0.53 & 0.40 & 0.47 \\
\hline 16 & Dryopteris varia & 0.4 & 0.5 & 0.5 & 0.5 & 0.5 & 0.4 & 0.47 & 0.47 & 0.47 \\
\hline
\end{tabular}


Table 3. Continued

\begin{tabular}{|c|c|c|c|c|c|c|c|c|c|c|}
\hline \multirow{2}{*}{$\begin{array}{l}\text { Target } \\
\text { No. }\end{array}$} & \multirow{2}{*}{$\frac{\text { Name }}{\text { Scientific name }}$} & \multicolumn{3}{|c|}{ Exposure } & \multicolumn{3}{|c|}{ Recovery } & \multicolumn{3}{|c|}{ Calculation } \\
\hline & & Height & Life cycle & $\begin{array}{l}\text { Economic } \\
\text { value }\end{array}$ & Sexes & $\begin{array}{l}\text { Florescence } \\
\text { and fruition }\end{array}$ & $\begin{array}{c}\text { Population } \\
\text { size }\end{array}$ & Ave (E) & Ave (R) & $\begin{array}{c}1 / 2(E) \\
+1 / 2(R)\end{array}$ \\
\hline 21 & Ranunculus chinensis & 0.4 & 1 & 0.25 & 0.5 & 0.25 & 0.4 & 0.55 & 0.38 & 0.47 \\
\hline 27 & Boehmeria tricuspis & 0.4 & 0.5 & 0.75 & 0.5 & 0.25 & 0.4 & 0.55 & 0.38 & 0.47 \\
\hline 36 & Silene firma & 0.4 & 0.5 & 0.75 & 0.5 & 0.25 & 0.4 & 0.55 & 0.38 & 0.47 \\
\hline 53 & Corchoropsis tomentosa & 0.4 & 1 & 0.25 & 0.5 & 0.25 & 0.4 & 0.55 & 0.38 & 0.47 \\
\hline 77 & Potentilla anemonifolia & 0.4 & 0.5 & 0.5 & 0.5 & 0.5 & 0.4 & 0.47 & 0.47 & 0.47 \\
\hline 86 & Lespedeza cuneata & 0.4 & 0.5 & 0.75 & 0.5 & 0.25 & 0.4 & 0.55 & 0.38 & 0.47 \\
\hline 95 & Dictamnus dasycarpus & 0.4 & 0.5 & 0.5 & 0.5 & 0.5 & 0.4 & 0.47 & 0.47 & 0.47 \\
\hline 107 & Agastache rugosa & 0.4 & 0.5 & 0.75 & 0.5 & 0.25 & 0.4 & 0.55 & 0.38 & 0.47 \\
\hline 112 & Isodon japonicus & 0.4 & 0.5 & 0.75 & 0.5 & 0.25 & 0.4 & 0.55 & 0.38 & 0.47 \\
\hline 122 & Melampyrum roseum & 0.4 & 1 & 0.25 & 0.5 & 0.25 & 0.4 & 0.55 & 0.38 & 0.47 \\
\hline 126 & Adenophora triphylla & 0.4 & 0.5 & 0.5 & 0.5 & 0.5 & 0.4 & 0.47 & 0.47 & 0.47 \\
\hline 133 & Artemisia capillaris & 0.4 & 0.5 & 0.75 & 0.5 & 0.25 & 0.4 & 0.55 & 0.38 & 0.47 \\
\hline 135 & Artemisia keiskeana & 0.4 & 0.5 & 0.75 & 0.5 & 0.25 & 0.4 & 0.55 & 0.38 & 0.47 \\
\hline 152 & Eupatorium lindleyanum & 0.4 & 0.5 & 0.5 & 0.5 & 0.5 & 0.4 & 0.47 & 0.47 & 0.47 \\
\hline 186 & Eriochloa villosa & 0.4 & 1 & 0.25 & 0.5 & 0.25 & 0.4 & 0.55 & 0.38 & 0.47 \\
\hline 200 & Allium sacculiferum & 0.4 & 0.5 & 0.5 & 0.5 & 0.5 & 0.4 & 0.47 & 0.47 & 0.47 \\
\hline 204 & Hemerocallis fulva & 0.4 & 0.5 & 0.75 & 0.5 & 0.25 & 0.4 & 0.55 & 0.38 & 0.47 \\
\hline 207 & Lilium tsingtauense & 0.4 & 0.5 & 0.5 & 0.5 & 0.5 & 0.4 & 0.47 & 0.47 & 0.47 \\
\hline 80 & Potentilla freyniana & 0.8 & 0.5 & 0.5 & 0.5 & 0.25 & 0.2 & 0.60 & 0.32 & 0.46 \\
\hline 205 & Hosta longipes & 0.6 & 0.5 & 0.5 & 0.5 & 0.25 & 0.4 & 0.53 & 0.38 & 0.46 \\
\hline 214 & Cephalanthera longibracteata & 0.6 & 0.5 & 0.5 & 0.5 & 0.25 & 0.4 & 0.53 & 0.38 & 0.46 \\
\hline 57 & Viola japonica & 0.8 & 0.5 & 0.25 & 0.5 & 0.25 & 0.4 & 0.52 & 0.38 & 0.45 \\
\hline 171 & Carex lanceolata & 0.8 & 0.5 & 0.25 & 0.5 & 0.25 & 0.4 & 0.52 & 0.38 & 0.45 \\
\hline 187 & Festuca ovina & 0.8 & 0.5 & 0.25 & 0.5 & 0.25 & 0.4 & 0.52 & 0.38 & 0.45 \\
\hline 87 & Sophora flavescens & 0.2 & 0.5 & 0.5 & 0.5 & 0.75 & 0.2 & 0.40 & 0.48 & 0.44 \\
\hline 136 & Artemisia princeps & 0.2 & 0.5 & 1 & 0.5 & 0.25 & 0.2 & 0.57 & 0.32 & 0.44 \\
\hline 151 & Eupatorium japonicum & 0.2 & 0.5 & 0.5 & 0.5 & 0.75 & 0.2 & 0.40 & 0.48 & 0.44 \\
\hline 46 & Polygonum senticosum & 0.2 & 1 & 0.25 & 0.5 & 0.25 & 0.4 & 0.48 & 0.38 & 0.43 \\
\hline 75 & Agrimonia pilosa & 0.2 & 0.5 & 0.75 & 0.5 & 0.25 & 0.4 & 0.48 & 0.38 & 0.43 \\
\hline 142 & Bidens frondosa & 0.2 & 1 & 0.25 & 0.5 & 0.25 & 0.4 & 0.48 & 0.38 & 0.43 \\
\hline 184 & Echinochloa crusgalli & 0.2 & 1 & 0.25 & 0.5 & 0.25 & 0.4 & 0.48 & 0.38 & 0.43 \\
\hline 30 & Achyranthes japonica & 0.4 & 0.5 & 0.75 & 0.5 & 0.25 & 0.2 & 0.55 & 0.32 & 0.43 \\
\hline 130 & Patrinia scabiosifolia & 0.2 & 0.5 & 0.5 & 0.5 & 0.5 & 0.4 & 0.40 & 0.47 & 0.43 \\
\hline 132 & Ambrosia artemisiifolia & 0.4 & 1 & 0.25 & 0.5 & 0.25 & 0.2 & 0.55 & 0.32 & 0.43 \\
\hline 138 & Aster scaber & 0.2 & 0.5 & 0.5 & 0.5 & 0.5 & 0.4 & 0.40 & 0.47 & 0.43 \\
\hline 180 & Calamagrostis arundinacea & 0.2 & 0.5 & 0.5 & 0.5 & 0.5 & 0.4 & 0.40 & 0.47 & 0.43 \\
\hline 5 & Equisetum arvense & 0.6 & 0.5 & 0.5 & 0.5 & 0.25 & 0.2 & 0.53 & 0.32 & 0.43 \\
\hline 69 & Rorippa indica & 0.6 & 0.5 & 0.5 & 0.5 & 0.25 & 0.2 & 0.53 & 0.32 & 0.43 \\
\hline 11 & Pteridium aquilinum & 0.4 & 0.5 & 0.5 & 0.5 & 0.25 & 0.4 & 0.47 & 0.38 & 0.43 \\
\hline 17 & Polystichum tripteron & 0.4 & 0.5 & 0.5 & 0.5 & 0.25 & 0.4 & 0.47 & 0.38 & 0.43 \\
\hline 83 & Desmodium podocarpum & 0.4 & 0.5 & 0.5 & 0.5 & 0.25 & 0.4 & 0.47 & 0.38 & 0.43 \\
\hline 99 & Peucedanum terebinthaceum & 0.4 & 0.5 & 0.5 & 0.5 & 0.25 & 0.4 & 0.47 & 0.38 & 0.43 \\
\hline 134 & Artemisia japonica & 0.4 & 0.5 & 0.5 & 0.5 & 0.25 & 0.4 & 0.47 & 0.38 & 0.43 \\
\hline 137 & Aster ageratoides & 0.4 & 0.5 & 0.5 & 0.5 & 0.25 & 0.4 & 0.47 & 0.38 & 0.43 \\
\hline 185 & Eragrostis ferruginea & 0.4 & 0.5 & 0.5 & 0.5 & 0.25 & 0.4 & 0.47 & 0.38 & 0.43 \\
\hline 172 & Carex leiorhyncha & 0.6 & 0.5 & 0.25 & 0.5 & 0.25 & 0.4 & 0.45 & 0.38 & 0.42 \\
\hline 191 & Paspalum thunbergii & 0.6 & 0.5 & 0.25 & 0.5 & 0.25 & 0.4 & 0.45 & 0.38 & 0.42 \\
\hline 179 & Arundinella hirta & 0.2 & 0.5 & 0.75 & 0.5 & 0.25 & 0.2 & 0.48 & 0.32 & 0.40 \\
\hline 196 & Setaria viridis & 0.2 & 1 & 0.25 & 0.5 & 0.25 & 0.2 & 0.48 & 0.32 & 0.40 \\
\hline 90 & Oenothera odorata & 0.4 & 0.5 & 0.5 & 0.5 & 0.25 & 0.2 & 0.47 & 0.32 & 0.39 \\
\hline 97 & Geranium thunbergii & 0.4 & 0.5 & 0.5 & 0.5 & 0.25 & 0.2 & 0.47 & 0.32 & 0.39 \\
\hline 98 & Angelica decursiva & 0.2 & 0.5 & 0.5 & 0.5 & 0.25 & 0.4 & 0.40 & 0.38 & 0.39 \\
\hline 128 & Galium verum & 0.4 & 0.5 & 0.5 & 0.5 & 0.25 & 0.2 & 0.47 & 0.32 & 0.39 \\
\hline 198 & Themeda triandra & 0.4 & 0.5 & 0.5 & 0.5 & 0.25 & 0.2 & 0.47 & 0.32 & 0.39 \\
\hline
\end{tabular}


Table 3. Continued

\begin{tabular}{|c|c|c|c|c|c|c|c|c|c|c|}
\hline \multirow{2}{*}{$\begin{array}{c}\text { Target } \\
\text { No. }\end{array}$} & \multirow{2}{*}{ Name } & \multicolumn{3}{|c|}{ Exposure } & \multicolumn{3}{|c|}{ Recovery } & \multicolumn{3}{|c|}{ Calculation } \\
\hline & & Height & Life cycle & $\begin{array}{l}\text { Economic } \\
\text { value }\end{array}$ & Sexes & $\begin{array}{l}\text { Florescence } \\
\text { and fruition }\end{array}$ & $\begin{array}{l}\text { Population } \\
\text { size }\end{array}$ & Ave (E) & Ave (R) & $\begin{array}{r}1 / 2(E) \\
+1 / 2(R)\end{array}$ \\
\hline 176 & Agropyron ciliare & 0.4 & 0.5 & 0.25 & 0.5 & 0.25 & 0.4 & 0.38 & 0.38 & 0.38 \\
\hline 177 & Agropyron tsukushiense & 0.4 & 0.5 & 0.25 & 0.5 & 0.25 & 0.4 & 0.38 & 0.38 & 0.38 \\
\hline 181 & Cymbopogon tortilis & 0.4 & 0.5 & 0.25 & 0.5 & 0.25 & 0.4 & 0.38 & 0.38 & 0.38 \\
\hline 183 & Digitaria sanguinalis & 0.4 & 0.5 & 0.25 & 0.5 & 0.25 & 0.4 & 0.38 & 0.38 & 0.38 \\
\hline 192 & Pennisetum alopecuroides & 0.4 & 0.5 & 0.25 & 0.5 & 0.25 & 0.4 & 0.38 & 0.38 & 0.38 \\
\hline 194 & Poa sphondylodes & 0.4 & 0.5 & 0.25 & 0.5 & 0.25 & 0.4 & 0.38 & 0.38 & 0.38 \\
\hline 41 & Polygonum filiforme & 0.4 & 0.5 & 0.25 & 0.5 & 0.25 & 0.2 & 0.38 & 0.32 & 0.35 \\
\hline 197 & Spodiopogon sibiricus & 0.2 & 0.5 & 0.25 & 0.5 & 0.25 & 0.4 & 0.32 & 0.38 & 0.35 \\
\hline 182 & Dactylis glomerata & 0.2 & 0.5 & 0.25 & 0.5 & 0.25 & 0.2 & 0.32 & 0.32 & 0.32 \\
\hline 188 & Miscanthus sinensis & 0.2 & 0.5 & 0.25 & 0.5 & 0.25 & 0.2 & 0.32 & 0.32 & 0.32 \\
\hline
\end{tabular}

\section{3. 결과 및 고찰}

초본 215종에 대한 화학물질 및 화학사고 대비 취약성 평 가를 수행한 결과, 환삼덩굴(Humulus japonicus) 및 아마 (Linum usitatissimum) (동률), 솔잎난(Psilotum nudum), 꽃마리 (Trigonotis peduncularis) 및 광대나물(Lamium amplexicaule) (동률) 순으로 화학사고에 취약한 것으로 평가되었다. 환삼 덩굴의 경우 일년초이며 경제적 가치가 높고(섬유 및 약용) 자웅이체라 화학사고에 취약하며 개화-결실기가 4개월 이상 으로 길기 때문에 가장 취약성 지수가 높았던 것으로 확인되 었으며 아마의 경우 일년초이며 경제적 가치가 높고(섬유, 약용, 기름의 원료) 국내 분포가 한정적(시도별 분류에서 3 개 지역에 분포)이기 때문이라는 점에서 동일하게 높은 취약 성 지수를 얻은 것으로 확인되었다. 다음 높은 취약성 지수 를 얻은 솔잎난의 경우, 낮은 높이와 높은 경제적 가치(관상 용 및 약용)로 높은 점수를 받은 것으로 확인되었다. 꽃마리 와 광대나물의 경우에는 두 식물 모두 낮은 높이와 상대적으 로 긴 개화-결실기로 인해 상대적으로 취약한 식물로 선정되 었다. 위와 같이 선정된 다섯 종의 가장 취약한 초본 식물의 경우, 양치식물인 솔잎난을 제외한 환삼덩굴, 아마, 꽃마리 및 광대나물의 경우에는 분류학적으로 진정쌍떡잎식물군 (Eudicots)으로 분류되는 종으로 목련류가 아닌 쌍떡잎식물 에 속한다. 이와는 반대로 상대적으로 가장 덜 취약한 생물 은 억새(Miscanthus sinensis), 오리새(Dactylis glomerata), 큰기 름새(Spodiopogon sibiricus), 이삭여뀌(Polygonum filiforme)인 것으로 확인되었다. 위 초본 식물들은 모두 약 $50 \mathrm{~cm}$ 이상의 상대적으로 큰 키가 특징이며 특별한 경제적 가치가 없고 개 화-결실 기간이 2 개월 이하로 짧으며 국내에서 넓은 서식 분 포(시도별 분류에서 12 개 이상의 지역에 분포)를 보이는 식 물들이었다. 또한 하위 취약종인 이삭여뀌를 제외한 억새, 오 리새 및 큰기름새는 본 연구에서 확인된 상대적으로 취약한 다섯 종의 초본 식물과는 반대로 외떡잎식물군(Monocots)에 속한다는 것이 확인되었다.
본 연구에서는 화학사고 및 화학물질에 대한 육상 초본 식물의 취약성을 평가하기 위한 기초적이고 개략적인 취약 성 평가 기법을 제안하였다. 그러나 선행 연구 ${ }^{33)}$ 에서 제시 한 일부 제한점은 여전히 보안되어야 할 문제로 남아있다. 절대적으로 부족한 육상 생태계 생물종의 독성 연구 자료, 지역적 정보가 반영되지 않았으므로 화학사고 발생 개연성 에 대한 자료 부족, 통합적 취약성평가를 위한 육상 생물종 에 대한 정보 부족 등의 현실적인 제한점들이 추후 연구들 에서 해결되어야 할 중요한 과제이다. 또한, 초본 식물의 취 약성 평가를 선행된 목본 식물에 대한 취약성평가와 함께 효과적으로 활용하기 위해서는 목본 및 초본 식물의 특성을 고려하여 화학사고 발생 시 취약성을 비교하기 위한 추가 연구가 필요할 것이다. 일반적으로 목본 식물은 초본 식물 에 비해 생물량(biomass)이 크고 외부 스트레스에 대한 민 감도(sensitivity)가 낮은 것으로 인지되고 있으나 이를 직간 접적으로 비교하여 목본 및 초본 식물의 취약성 평가를 효 과적으로 수행할 수 있는 방안을 마련하는 것이 필요하다.

\section{4. 결 론}

현대사회에서 화학물질의 중요성은 이루 말할 수 없을 정 도로 크며, 그 분야를 막론하고 모든 인간 활동에 화학물질 이 사용된다고 하여도 과언이 아닐 정도로 다양하고도 많은 양의 화학물질이 현대사회에서 생산, 유통, 사용 및 폐기되 고 있다. 이러한 화학물질이 인간 활동에 의해 환경 중으로 노출되고 있으며 이에 대한 연구도 지속적으로 수행되고 있 으나 비의도적으로 발생할 수 있는 화학사고에 대한 대응책 이나 이에 대한 연구는 아직도 미흡한 것이 현실적인 문제 로 남아있다. 육상 생태계는 다양한 생물 및 인간 활동의 배 경이며 이에 따라 필연적으로 화학사고 발생의 가능성이 매 우 높기 때문에 이를 사전에 대비하고 화학사고 발생 시 이 를 효과적으로 관리할 수 있는 시스템을 마련하는 것이 반 드시 필요하다. 
본 연구에서는 이전에 수행되었던 화학물질 및 화학사고 에 대한 목본류 취약성 평가구에 이어 초본류에 대한 취약 성 평가를 시범적으로 수행하고 이를 추후 다른 육상 생물 종에 적용할 수 있는 프레임 워크를 제안하는 것을 목표로 하였다. 그러나 여전히 육상 생태계 취약성 평가 기법에 활 용할 수 있는 화학물질 독성에 대한 연구의 부족 및 식물 외 생물종에 대한 자료 부족이라는 제한점이 존재하므로 추 후 상당한 추가 연구가 필요할 것으로 사료된다. 목본 식물 에 대한 선행연구 및 초본 식물에 대한 본 연구의 준비 단 계에서는 다양한 식물의 특성을 반영하여 취약성 평가를 수 행하고자 보다 다양한 인자들(목본 식물의 목질 밀도와 상 록 또는 하록 여부; 초본 식물의 직경과 군집 형성 속도, 잎 의 모양 및 형태 등)을 활용하고자 하였으나 자료 및 대상 연구부족의 한계점으로 인해 충분한 자료 활용이 어려웠다 는 문제점이 존재하였다. 특별히 목본 식물의 목질 밀도와 내구도 및 초본 식물의 군집 형성 능력 등을 취약성 평가에 반영할 수 있다면 더욱 신뢰도 높은 취약성 평가를 수행할 수 있었을 것으로 예상된다. 이러한 제한점을 극복하기 위 해서는 화학사고의 발생 가능성, 사고대비 화학물질에 대한 독성 자료 생산, 육상 서식 생물종에 대한 특성 및 민감도에 대한 연구가 지속적으로 수행될 필요가 있다. 그러나 현실 적으로 모든 위험에 대비할 수 없기 때문에 우선적으로 화 학사고 및 화학물질에 취약한 지역과 그 생태계를 선정하여 관리하고 보호하는 것이 필요하며, 본 연구에서 제안하는 육상 생태계 취약성 평가 기법은 이러한 문제를 효과적으로 처리할 수 있는 수단으로 사용될 수 있을 것이다. 따라서 추 가적인 연구를 수행하고 이를 사용하여 기법을 보완, 화학 사고 및 화학물질에 취약한 육상 환경을 효과적으로 관리하 는 것이 인간과 환경을 사고로부터 보호할 수 있는 좋은 수 단으로 사용될 수 있다.

\section{Acknowledgements}

This work was supported by Korea Environment Industry \& Technology Institute (KEITI) through "The Chemical Accident Prevention Technology Development Project", funded by Korea Ministry of Environment (MOE) (No. 2016001970001). This study was also funded by the MOE as the Graduate School of Specialization for Safe Management of Chemicals.

\section{References}

1. V. Torsvik, L. Øvreås, Microbial diversity and function in soil: from genes to ecosystems, Curr. Opin. Microbiol., 5(3), 240-245(2002).

2. D. Kim, S. W. Kim, Y. J. An, Research trend for on-site soil ecotoxicity evaluation methods for field soil, J. Korean Soc. Environ. Eng., 41(3), 125-131(2019).

3. R. L. Heath, S. Seshadri, J. Lee, Risk communication: a two-community analysis of proximity, dread, trust, involvement, uncertainty, openness/accessibility, and knowledge on support/opposition toward chemical companies, J. Public Relat. Res., 10(1), 35-56(1998).

4. S. Y. Cho, K. H. Woo, J. S. Kim, S. Y. Yoon, J. Y. Na, J. H. Yu, Y. B. Kim, Acute symptoms in firefighters who participated in collection work after the community hydrogen fluoride spill accident, Ann. Occup. Environ. Med., 25(1), 36(2013).

5. I. J. Shin, Major industrial accidents in Korea: the characteristics and implication of statistics 1996-2011, Process Saf. Prog., 32(1), 90-95(2013).

6. J. An, H. A. Lee, J. Lee, H. O. Yoon, Fluorine distribution in soil in the vicinity of an accidental spillage of hydrofluoric acid in Korea, Chemosphere, 119, 577-582(2015).

7. K. Jung, H. W. Park, Tracing interorganizational information networks during emergency response period: a webometric approach to the 2012 Gumi chemical spill in South Korea, Gov. Inf. Q., 33(1), 133-141(2016).

8. K. Lee, H. M. Kwon, S. Cho, J. Kim, I. Moon, Improvements of safety management system in Korean chemical industry after a large chemical accident, J. Loss. Prev. Process. Ind., 42, 6-13(2016).

9. P. R. Kim, D. Y. Kim, Y. J. Han, A review for the long-term trend and spatial distribution of soil mercury concentration in South Korea, J. Korean Soc. Environ. Eng., 41(6), 346-355(2019).

10. M. U. Kim, S. Shin, S. H. Byeon, Comparison of chemical risk assessment methods in South Korea and the United Kingdom, J. Occup. Health. Psychol., 57(4), 339-345(2015).

11. M. S. Kim, E. B. Lee, T. Ryu, J. Y. Kim, J. Yoon, Improvement of risk analysis of off-site risk assessment by parallel system, J. Korean Soc. Environ. Eng., 40(4), 163-170(2018).

12. N. S. Jung, D. H. Jang, S. H. Lee, Research on an upland indicator plant for vulnerability assessment of climate change, The Association of Korean Photo-Geographers, 19(4), 81-93(2009).

13. Y. J. Oh, M. H. Kimg, Y. E. Na, S. H. Hong, W. K. Paik, S. T. Yoon, Vulnerability assessment of soil loss in farm area to climate change adaption, Korean J. Soil Sci. Fert., 45(5), 711-716(2012).

14. M. H. Kim, H. S. Bang, Y. E. Na, M. Kim, Y. J. Oh, K. K. Kang, K. J. Cho, Vulnerability assessment of rice production by main disease and pest of rice plant to climate change, J. Korea Env. Res. Tech., 16(1), 147-157(2013).

15. S. J. Kim, S. M. Kim, S. M. Kim, A study on development of vulnerability assessment criteria for agricultural infrastructure according to climate change, J. Agric. Life Sci., 47(1), 205-213(2013).

16. J. B. Lee, H. J. Lee, K. J. Moon, S. C. Hong, D. R. Kim, C. K. Song, Y. D. Hong, Vulnerability assessment of human 
health sector due to climate change: focus on ozone, J. Korean. Soc. Atmos. Environ., 28(1), 22-38(2012).

17. H. Yoo, J. Kim, J. Shin, Y. Kim, S. Min, D. Jegal, K. Bang, S. Lee, Health vulnerability assessment for PM10 due to climate change in Incheon, J. Environ. Health. Sci., 43(3), 240-246(2017).

18. S. R. Lee, S. H. Choi, Groundwater pollution susceptibility assessment of Younggwang area using GIS technique, J. Korean Soc. Groundwater Environ., 4(4), 223-230(1997).

19. S. Y. Hamm, J. Y. Cheong, M. J. Kim, I. S. Kim, H. S. Hwang, Assessing groundwater vulnerability using DRASTIC method and groundwater quality in Changwon city, Econ. Environ. Geol., 37(6), 631-645(2004).

20. M. J. Lee, Y. J. Hyun, S. I. Hwang, An assessment of groundwater contamination vulnerability and priority areas for groundwater management using GIS and analytic hierarchy process, J. Korean Assoc. Geogr. Inf. Stud., 18(3), 35-51(2015).

21. K. T. Kim, S. G. Jung, K. H. Park, J. H. Oh, Evaluation of landslide susceptibility using GIS and RS, J. Korean Assoc. Geogr. Inf. Stud., 8(1), 75-87(2005).

22. Y. K. Yeon, Evaluation and analysis of Gwangwon-do landslide susceptibility using logistic regression, J. Korean Assoc. Geogr. Inf. Stud., 14(4), 116-127(2011).

23. T. S. Shon, D. H. Kang, J. K. Jang, H. S. Shin, A study of assessment for internal inundation vulnerability in urban area using SWMM, J. Korean Soc. Hazard Mitig., 10(4), 105-117(2010).

24. B. G. Song, T. S. Lee, K. H. Park, Assessment of flooding vulnerability based on GIS in urban area-focused on Changwon city, J. Korean Assoc. Geogr. Inf. Stud., 17(4), 129-143(2014).

25. S. Lee, E. M. Chang, Application of GIS to typhoon risk assessment, Spat. Inf. Res., 17(2), 243-249(2009).

26. J. E. Kang, M. J. Lee, Assessment of flood vulnerability to climate change using fuzzy model and GIS in Seoul, J. Korean Assoc. Geogr. Inf. Stud., 15(3), 119-136(2012).

27. J. Chakraborty, M. P. Armstrong, Using geographic plume analysis to assess community vulnerability to hazardous accidents, Comput. Environ. Urban. Syst., 19(5-6), 341-356 (1995).

28. T. Aoki, R. Ceravolo, A. De Stefano, C. Genovese, D. Sabia, Seismic vulnerability assessment of chemical plants through probabilistic neural networks, Reliab. Eng. Syst. Saf., 77(3), 263-268(2002).

29. C. D. Jaeger, Chemical facility vulnerability assessment project, J. Hazard. Mater., 104(1-3), 207-213(2003).

30. F. Li, J. Bi, L. Huang, C. Qu, J. Yang, Q. Bu, Mapping human vulnerability to chemical accidents in the vicinity of chemical industry parks, J. Hazard. Mater., 179(1-3), 500-506 (2010).

31. F. Argenti, G. Landucci, G. Reniers, V. Cozzani, Vulnerability assessment of chemical facilities to intentional attacks based on Bayesian network, Reliab. Eng. Syst. Saf., 169, 515-530(2018).

32. S. J. Ki, K. H. Kim, H. G. Lee, K. H. Shin, Review of soil vulnerability assessment tools in Korea and other developed contries, J. Korean Soc. Environ. Eng., 39(12), 741-749(2017).

33. Y. Chae, R. Cui, J. Lee, L. Kim, Y. J. An, Development of methodology for vulnerability assessment of chemical accident in terrestrial ecosystem: (1) focusing on the trees, J. Korean Soc. Environ. Eng., 42(5), 229-238(2020).

34. National Institute of Biological Resources, National species list of Korea, http://www.kbr.go.kr/stat/ktsnfiledown/down popup.do(2017).

35. Ministry of Environment, Data Book of National Ecosystem Survey 1(2017).

36. Y. N. Lee, New Flora of Korea, Kyohaksa, Seoul, Korea (2006).

37. Korea Forest Service, Nature, http://www.nature.go.kr(2009).

38. Korea Forest Service, A Field Guide to Trees \& Shrubs, Geobook, Seoul, Korea(2010).

\section{Authors}

\section{Yooeun Chae}

Department of Environmental Health Science, Konkuk University, Researcher, ORCID(0) 0000-0002-4060-6838

\section{Lia Kim}

Department of Environmental Health Science, Konkuk University, Graduate Student, ORCID (D) 0000-0001-5509-9341

\section{Rongxue Cui}

Department of Environmental Health Science, Konkuk University, Graduate Student, ORCID (D) 0000-0003-1197-6044

\section{Jieun Lee}

Department of Environmental Health Science, Konkuk University, Graduate Student, ORCID(D) 0000-0001-9362-4143

\section{Youn-Joo An}

Department of Environmental Health Science, Konkuk University, Professor, ORCID (D) 0000-0002-0193-1929 